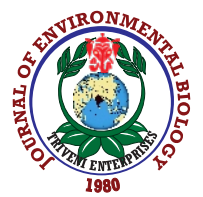

\title{
Technical efficiency of Indian farmers in sugarcane production-A panel stochastic frontier approach
}

\author{
K.T. Felix ${ }^{1 *}$, M. Umanath ${ }^{1}$, P.N. Kumar ${ }^{2}$ and N.K. Meena ${ }^{3}$ \\ 'Department of Economics, Madras Institute of Development Studies, Chennai-600 020, India \\ ${ }^{2}$ Department of Agricultural Economics, Tamil Nadu Agricultural University, Coimbatore-641 003, India \\ ${ }^{3}$ Department of Agricultural Economics, Sardar Vallabh Bhai Patel University of Agriculture and Technology, Meerut-250 110, India \\ *Corresponding Author Email : felixtheeconomist@gmail.com
}

\section{Abstract}

Aim: To estimate the technical inefficiency of Indian farmers in sugarcane production.

Methodology: Although various stochastic frontier models for panel data are available, six of them were considered for the study, which is frequently applied in empirical research. Based on the log likelihood ratio, results are interpreted only for kumbhakar, lien and hardaker (KLH) model.

Results: Indian farm's overall technical efficiency ranged from minimum 0.11 to maximum 0.93 with a mean value of 0.70 , it means that with same resource based average sugarcane growers can increase their yield up to $23 \%$ and most technical inefficient grower can increase their yield up to $82 \%$ in order to achieve overall technical efficiency level (93\%) of efficient fellow grower in study area. Though, Tamil Nadu has the highest overall technical efficiency score in sugarcane production (0.76), the negative growth rate indicates its decline in technical efficiency. Haryana has a negative growth rate in persistent, residual and overall technical efficiency in sugarcane production.

Interpretation: Among the seven states, Uttaranchal showed the highest scope of improving the sugarcane yield with 36\%, followed by Uttar Pradesh $(34 \%)$, Haryana (33\%), Maharashtra (30\%), Karnataka (30\%), Andhra Pradesh (25\%) and Tamil Nadu (24\%). Results of parameter estimates confirmed that area in hectare, machine usage in hours, seed quantity in kilograms, manure usage in quintals and total fertilizer usage in kilograms are significant and positively influence the sugarcane production. The coefficients of dummy for farm size reveals that medium and large sugarcane farms are less efficient compared to small farms. Similarly, the share of own machine-hours has a negative impact on sugarcane production. Based on the empirical results appropriate policy is suggested for the study.

Key words: Frontier, Panel data, Production, Sugarcane, Technical efficiency

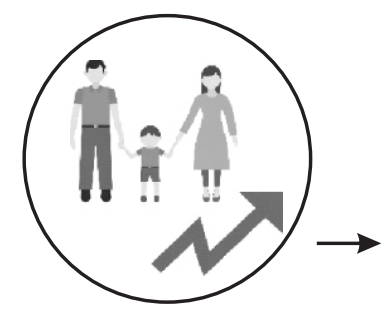

Increased population

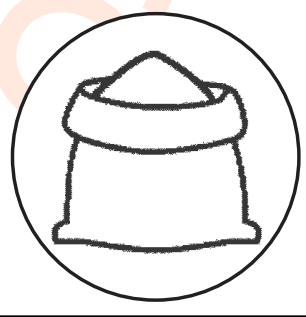

Increased sugar demand

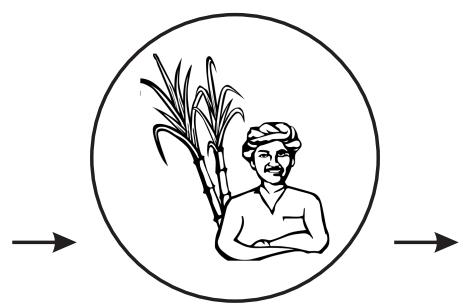

Can achieve only with efficient cane production

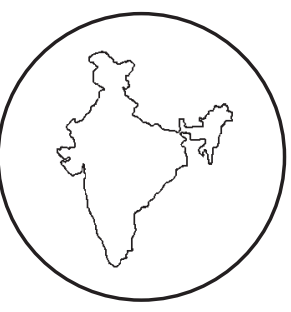

Need to find, how farmers are efficient

How to cite : Felix, K.T., M. Umanath, P.N. Kumar and N.K. Meena: Technical efficiency of Indian farmers in sugarcane production-A panel stochastic frontier approach. J. Environ. Biol., 41, 1611-1620 (2020). 


\section{Introduction}

Agriculture and allied sector in India contribute $17.32 \%$ to gross domestic product (MoSPI, 2020). Sugar industry is the second largest agro-based industry in India next to textiles. It plays a vital role in the agricultural and industrial economy. Though sugarcane and sugar beet are the main sources of sugar in the world. Most of the sugar in India is produced only from sugarcane. More than $80 \%$ of the world's share in sugarcane production and area is contributed by Brazil, China-mainland, Colombia, Cuba, India, Mexico, Pakistan, Philippines, Thailand and the United States of America (FAOSTAT, 2018). Brazil ranks first in area (10.04 million ha with a share of $38.22 \%$ ) and production (746 million tons with a share of $39.16 \%$ ) of sugarcane. India occupies a second major share in the area as well as production with a share of $18.00 \%$ (4.73 million ha) and $19.76 \%$ (376.90 million tons), respectively. The productivity of India's sugarcane (69.74 tons per hectare) is lesser than the world's productivity (79.68 tons per hectare), though it ranks second in area and production. Sugarcane accounts for $3.2 \%$ of net sown area, $95.53 \%$ of irrigated area and $5.45 \%$ percent of total fertilizer consumption. In 2018-19, Uttar Pradesh occupied a major share in sugarcane area (43.93\%) and production (44.33\%) but states like Puducherry, Kerala and Tamil Nadu occupied top position in sugarcane productivity.In the case of productivity, Peru has the highest productivity with a yield of 121.83 tons per hectare. On the other hand, India's per capita sugar consumption has been growing at a steady rate of $3 \%$ and is currently $19.5 \mathrm{~kg}$. Because of high domestic demand and occasional fluctuation in production, India has a minimal share in sugar export (Solomon, 2011). The sugar demand of the country is growing consistently with population growth. Without the contribution of efficient sugarcane production, meeting such a huge domestic demand for sugar is impossible and would have warranted massive sugar import (Malaiarasan et al., 2019). Production of sugarcane depends on the use and combination of inputs. These combinations are considered as Technology. Variations in technology affects sugarcane yield. Many studies have confirmed that there is a gap between potential and realized yield of sugarcane in India (Surendran et al., 2016; Rao, 2012; Shanthy, 2011). Particularly in developing countries like India, inefficiency in production is one of the core factors hindering the exploitation of full potential of innovated technologies (Sekhon et al., 2010; Kalirajan and Shand, 1989; Banik, 1994; Thomas and Sundaresan, 2000). Variations in the input management and output levels among farms are varying over the years. Therefore, it is not enough to know how farms are technically efficient but how farms are persistent in production technical efficiency will be helpful to meet our future sugar demand. With this scenario, the core objective of this study was to assess how overall technical efficiency and persistent technical efficiency in sugarcane production vary over the years and across states and to assess the relationship of technical efficiency on firm size and share of own machine hours.

\section{Materials and Methods}

Cost of cultivation of principal crops (CCPC) data was used for this study. This data was collected from a comprehensive survey initiated in 1970-71. This survey covered 29 crops (choice and the number of crops depend on their importance to the State) covering 16 states. The data considered for the present study is an unbalanced farm-level panel data from 2011-12 to 2013-14 with time gaps. This panel data consists of 944 observations from seven states (Andhra Pradesh, Haryana, Karnataka, Maharashtra, Tamil Nadu, Uttar Pradesh and Uttaranchal). Estimated inefficiency with cross-section data has been reported (Parikh and Shah, 1994; Dlamini et al., 2010; Felix et al., 2018; Ambetsa et al., 2020). But, estimating inefficiency with crosssection data have three major problems (Schmidt and Sickles, 1984). First, the formula used to estimate inefficiency index (JLMS) depends on distributional assumptions for the noise and inefficiency components. An assumption, at least for a single equation the technical inefficiency component should be independent of regressors is unlikely true if firms maximize profit (Mundlak, 1961). Finally, when the cross-sectional units are more the conditional mean $u(v-u)$ never approaches $u$, leading to inefficiency index estimator as an inconsistent one. Hence, panel data was used for this study. Panel data has an advantage over cross-sectional which takes into account of heterogeneity by introducing individual effect (time-invariant and individualspecific).

Model 1 : Pitt and Lee, 1981 (Time-Invariant Technical Inefficiency model) : This model assumes that efficiency is individual specific and time variant. It can be written as

$$
\begin{aligned}
& y_{i t}=f\left(x_{i t} ; \beta\right)+\epsilon_{i t}, \\
& \epsilon_{i t}=v_{i t}-u_{i}, u_{i} \geq 0, i=1, \ldots \ldots, N ; t=1, \ldots, T
\end{aligned}
$$

where, $f\left(\mathrm{x}_{\mathrm{it}} ; \beta\right)$ is a linear function of the variables in the vector $\mathrm{x}_{\mathrm{it}}$ and $u_{i} \geq 0$ is the time-invariant technical inefficiency of individual $i$. This model can be estimated by assuming either $u_{i}$ is a fixed (Fixed effect model) or a random variable (Random effect model). In fixed and random effect model, $u_{i}$ does not follow any distribution. Although distribution-free assumption may be desirable, it can also estimate with MLE by imposing distributional assumptions on $\mathrm{v}_{\mathrm{it}}$ and $\mathrm{u}_{\mathrm{i}}$ (Pitt and Lee, 1981).

\section{It can be written as}

$$
\begin{aligned}
& \mathrm{y}_{\mathrm{it}}=f\left(\mathrm{x}_{\mathrm{it}} ; \beta\right)+\epsilon_{\mathrm{it},} \\
& \epsilon_{\mathrm{it}}=\mathrm{v}_{\mathrm{it}}-\mathrm{u}_{\mathrm{i}}, \\
& \mathrm{v}_{\mathrm{it}} \sim \mathrm{N}\left(0, \sigma_{\mathrm{v}}^{2}\right) \text { and ui } \sim \mathrm{N}^{+}\left(\mu, \sigma_{\mathrm{u}}^{2}\right) .
\end{aligned}
$$

The likelihood function for $i^{\text {th }}$ observation is presented below 


$$
\begin{aligned}
& \ln L i=\text { constant }+\ln \phi\left(\frac{\mu_{i^{*}}}{\sigma_{*}}\right)+\frac{1}{2} \ln \left(\sigma_{*}^{2}\right)-\frac{1}{2}\left\{\frac{\sum_{t} \epsilon_{i t}^{2}}{\sigma_{2 v}}+\left(\frac{\mu}{\sigma_{u}}\right)^{2}-\right. \\
&\left.\left(\frac{\mu_{i^{*}}}{\sigma_{*}}\right) 2\right\}-T \ln \left(\sigma_{v}\right)-\ln \phi\left(\frac{\mu}{\sigma_{u}}\right)
\end{aligned}
$$

Model 2 : Kumbhakar, 1990 and Model 3 : Battese Coelli, 1992 (Time-Varying Inefficiency Models with Deterministic and Stochastic Components) : In this model, the inefficiency term $u_{\text {it }}$ is not fixed, it varies over time and across individuals. This $u_{i t}$ has two distinct inefficient components $\mathrm{G}(\mathrm{t})$. First is a non-stochastic time component and the second is a stochastic individual component $u_{i t}$.

$\mathrm{y}_{\mathrm{it}}=f\left(\mathrm{x}_{\mathrm{it}} ; \beta\right)+\epsilon_{\mathrm{it}}$

$\epsilon_{\mathrm{it}}=\mathrm{v}_{\mathrm{it}}-\mathrm{u}_{\mathrm{it}}$

$u_{i t}=G(t) u_{i}, v_{i t} \sim N\left(0, \sigma_{v}^{2}\right)$ and $u i \sim N+\left(u, \sigma_{u}^{2}\right)$, where $G(t)>0$ is a function of $(\mathrm{t})$.

Based on the forms of $\mathrm{G}(\mathrm{t})$ Model 2 and 3 were considered for the study Kumbhakar (1990) model assumes $G(t)=\left[1+\exp \left(\gamma_{1} t+\right.\right.$ $\left.\left.\gamma_{2} t^{2}\right)\right]^{-1}$ and Battese Coelli (1992) model assumes $\mathrm{G}(\mathrm{t})=\exp (\gamma(\mathrm{t}-$ $\mathrm{T})$ ], where $\mathrm{T}$ is the terminal period of the sample.

Model 4 : Greene, 2005 (Separate Firm Heterogeneity from Inefficiency) : This model consist a persistent inefficiency term. It also represents individual specific effect (heterogeneity).

$$
y_{i t}=\alpha_{i}+x_{i t}^{\prime} \beta+v_{i t}-u_{i t}
$$

The term $-\mathrm{u}_{\mathrm{it}}$ represents time varying inefficiency and this model treats $\alpha_{i}, i=1, \ldots, N$ as a fixed parameter. (Greene, 2005).

Model 5 : Kumbhakar and Heshmati, 1995 (Separate Persistent and Time-Varying Inefficiency) : The persistent inefficiency reflects the effect of inputs like management as well as other unobserved inputs which vary across firms but not over time unless a change in government policy, change in firmownership and so on (Mundlak, 1961). In contrast, the residual inefficiency component might change over time without any change in the operation of the firm.

yit $=\beta_{0}+x^{\prime}$ it $\beta+\in$ it,

$\epsilon_{\mathrm{it}}=\mathrm{v}_{\mathrm{it}}-\mathrm{u}_{\mathrm{it}}$,

$\mathrm{u}_{\mathrm{it}}=\mathrm{u}_{\mathrm{i}}+\mathrm{T}_{\mathrm{it}}$

here the error term $\epsilon_{\mathrm{it}}$, is decomposed into two $\left(\epsilon_{\mathrm{it}}=\mathrm{v}_{\mathrm{it}}-\mathrm{u}_{\mathrm{it}}\right)$, where, $u_{i t}$ is technical inefficiency and $v_{i t}$ is random error. The technical inefficiency term further decomposed into two terms $\left(u_{i t}\right.$ $=u_{i}+T_{i t}$ ), where $u_{i}$ is the time invariant persistent component and $T_{\text {it }}$ is time varying residual inefficiency term. The persistent component is firm specific but residual term is both firm and time specific.
Model 6 : Kumbhakar, Lien and Hardaker, 2014 (Separate Firm Effects, Persistent Inefficiency and Time-Varying Inefficiency) : This model was introduced by Kumbhakar, Lien, and Hardaker (2014) and Colombi et al. (2014). It overcomes some of the limitations of the above said model. By taking into account of different factors affects output for given level of input, the error term is split into four components of which two $\left(n_{i}\right.$ and $\left.u_{i t}\right)$ are inefficiency term and other two are firm effect $\left(\mu_{\mathrm{i}}\right)$ and noise $\left(v_{i t}\right)$.

$$
\mathrm{y}_{\mathrm{it}}=\mathrm{a}_{0}+f\left(\mathrm{x}_{\mathrm{it}} ; \beta\right)+\mu_{\mathrm{i}}+\mathrm{v}_{\mathrm{it}}-\mathrm{n}_{\mathrm{i}}-\mathrm{u}_{\mathrm{it}}
$$

The first component captures firm's latent heterogeneity (Greene, 2005), second component captures time varying inefficiency, third component captures persistent or time invariant inefficiency (Kumbhakar and Hjalmarsson, 1993,1995; Kumbhakar and Heshmati, 1995) and last component captures random noise.

For the present study, the above model was estimated by single stage maximum likelihood method based on distributional assumptions on the four components (Colombi et al., 2011)

The above equation is rewritten as

$\mathrm{y}_{\mathrm{it}}=\alpha_{0}^{*}+f\left(\mathrm{x}_{\mathrm{it}} ; \beta\right)+\alpha_{\mathrm{i}}+\epsilon_{\mathrm{it}}$

where, $\alpha_{0}^{*}=a_{0}-E\left(n_{i}\right)-E\left(u_{i t}\right) ; \alpha_{i}=\mu-n_{i}+E\left(n_{i}\right) ;$ and $\epsilon_{i t}=v_{i t}-u_{i t}-$ $\mathrm{E}\left(\mathrm{u}_{\mathrm{it}}\right)$

The above model was estimated in three steps

Step 1: Random effect panel regression was performed to estimate $\beta$. This estimation also provided predicted values of $\alpha_{i}$ and $\in_{\text {itt }}$

Step 2: The time varying technical inefficiency $\left(u_{i t}\right)$ was estimated from predicted values of $\epsilon_{\mathrm{it}}$. Standard stochastic frontier technique $\epsilon_{\mathrm{it}}=\mathrm{v}_{\mathrm{it}}-\mathrm{u}_{\mathrm{it}}-\mathrm{E}\left(\mathrm{u}_{\mathrm{it}}\right)$ was used to estimate the time varying residual technical inefficiency term $u_{i t}$ (Jondrow et al., 1982). By assuming $v_{\text {it }}$ is i.i.d. $\mathrm{N}\left(0, \sigma_{v}^{2}\right)$ and $u_{i t}$ is $\mathrm{N}^{+}\left(0, \sigma_{u}^{2}\right)$, which means $E\left(u_{i t}\right)=\left(\sqrt{ } 2 / \pi \sigma_{u}\right)$.

Step $3: n_{i}$ was estimated from the best linear predictor of $\alpha_{i}$ from step 1. This persistent technical inefficiency was estimated from PTE $=\exp \left(-n_{i}\right)$, The overall technical efficiency was obtained by multiplying the persistent- and residual-technical efficiency.

Variables employed for the present study

Dependent variable : In_YLD : Natural logarithm of sugarcane production in quintals

Independent variables : In_ARE : Natural logarithm of total area used for cane production in hectares; In_ANL : Natural logarithm of total animal labour used for cane production in hours; In_MCN : 
Natural logarithm of total machine labour used for cane production in hours; In_SED : Natural logarithm of total seed used for cane production in kilograms; In_MRE : Natural logarithm of total manures used for cane production in quintals; In_INC : Natural logarithm of total insecticides used for cane production in rupees; In_FER: Natural logarithm of total fertilizers used for cane production in kilograms; In_SMC : Natural logarithm of share of own machine hours used for cane production in hours (it's the ratio of own machine hours divided by total machine hours); SDU2: Dummy for medium firm $=1$, if the area is $>2$ ha to $<=4$ ha; otherwise=0; SDU3 : Dummy for large firm=1, if the area is $>4$ ha; otherwise $=0$

\section{Results and Discussion}

The descriptive statistics of model are presented in Table 1. It is evident that an average of 1.50 ha sugarcane farm produces an average of 1205.25 quintal sugarcane with $39.47 \mathrm{hrs}$ of animal labor, $26.08 \mathrm{hrs}$ of machine labor, 55.19 quintals of manures, 1028.89 rupees of insecticide cost and 578.12 kilograms of fertilizers. It is evident from Fig. 1, Model-4 had the highest mean technical efficiency of 0.74 because it did not consider the firm effects to be inefficiency, leading to highefficiency scores (Fig. 1) and low dispersion (Fig. 2). Greene
(2005) also found in a study of the US banking industry that the 'true' random effects results had higher and less dispersed technical efficiency scores than results for other models considered. Similarly, Model-5 had the lowest mean technical efficiency of 0.37 because it has the assumption that inefficiency won't change over the period.

Model- 6 overcomes the problem of Model- 4 and -5 by decomposing the time-persistent noise into a firm effect and a persistent technical inefficiency effect. The efficiency scores of Model- 6 lies between the scores for Models-4 and -5 (Fig.2). The mean overall efficiency score for Model 6 is 0.70 , and the score spread is between that of Model 4 (low spread) and Model-5 (high spread; Fig. 2).

A perfect match between the two models would showed up as presence of straight line in the graph revealing perfect match between the two models. The pattern of results between Model- 1 and -2 , Model-1 and -3, Model-2 and -3 , and between Model- 5 and -6 seem to be most consistent, i.e., these model comparisons have least dispersed scatter plots, strongest congruence, and most consistent rankings. The scatter plot between Models- 1 and -2, Model- 1 and -3 , Model-2 and -3 seem quite linear with high correlation values of $0.9993,0.9891$ and

Table 1: Descriptive statistics

\begin{tabular}{|c|c|c|c|c|c|c|}
\hline Variable & & Mean & Std. Dev. & Min & Max & Observations \\
\hline \multirow[t]{3}{*}{ YLD } & overall & 1205.24 & 1360.41 & 6.50 & 18721.25 & $N=2018$ \\
\hline & between & & 1206.69 & 6.83 & 12762.28 & $n=944$ \\
\hline & within & & 566.43 & -4753.74 & 8940.07 & bar $=2.13$ \\
\hline \multirow[t]{3}{*}{ ARE } & overall & 1.50 & 1.48 & 0.02 & 20.09 & $N=2018$ \\
\hline & between & & 1.34 & 0.02 & 14.87 & $\mathrm{n}=944$ \\
\hline & within & & 0.55 & -5.66 & 8.66 & bar $=2.13$ \\
\hline \multirow[t]{3}{*}{ ANL } & overall & 39.47 & 89.37 & 0.00 & 1443.00 & $N=2018$ \\
\hline & between & & 80.46 & 0.00 & 941.00 & $n=944$ \\
\hline & within & & 40.62 & -716.53 & 541.47 & bar $=2.13$ \\
\hline \multirow[t]{3}{*}{$\mathrm{MCN}$} & overall & 26.08 & 50.01 & 0.00 & 529.50 & $N=2018$ \\
\hline & between & & 43.59 & 0.00 & 352.00 & $\mathrm{n}=944$ \\
\hline & within & & 25.13 & -188.58 & 262.92 & bar $=2.13$ \\
\hline \multirow[t]{3}{*}{ SED } & overall & 42.03 & 67.58 & 0.00 & 1069.00 & $N=2018$ \\
\hline & between & & 49.19 & 0.00 & 479.67 & $n=944$ \\
\hline & within & & 47.40 & -437.64 & 631.36 & bar $=2.13$ \\
\hline \multirow[t]{3}{*}{ MRE } & overall & 55.19 & 506.77 & 0.00 & 17915.00 & $N=2018$ \\
\hline & between & & 430.79 & 0.00 & 11283.13 & $n=944$ \\
\hline & within & & 270.41 & -6576.69 & 6687.06 & bar $=2.13$ \\
\hline \multirow[t]{3}{*}{ INC } & overall & 1028.89 & 3480.71 & 0.00 & 79495.81 & $N=2018$ \\
\hline & between & & 2895.84 & 0.00 & 60443.68 & $n=944$ \\
\hline & within & & 1702.48 & -22638.20 & 41888.08 & bar $=2.13$ \\
\hline \multirow[t]{3}{*}{ FER } & overall & 578.12 & 734.90 & 0.00 & 9891.50 & $N=2018$ \\
\hline & between & & 663.21 & 0.00 & 7708.75 & $n=944$ \\
\hline & within & & 301.43 & -1987.52 & 3604.12 & bar $=2.13$ \\
\hline \multirow[t]{3}{*}{ SMC } & overall & 0.27 & 0.41 & 0.00 & 1.00 & $N=1486$ \\
\hline & between & & 0.39 & 0.00 & 1.00 & $n=810$ \\
\hline & within & & 0.11 & -0.40 & 0.93 & bar $=2.13$ \\
\hline
\end{tabular}



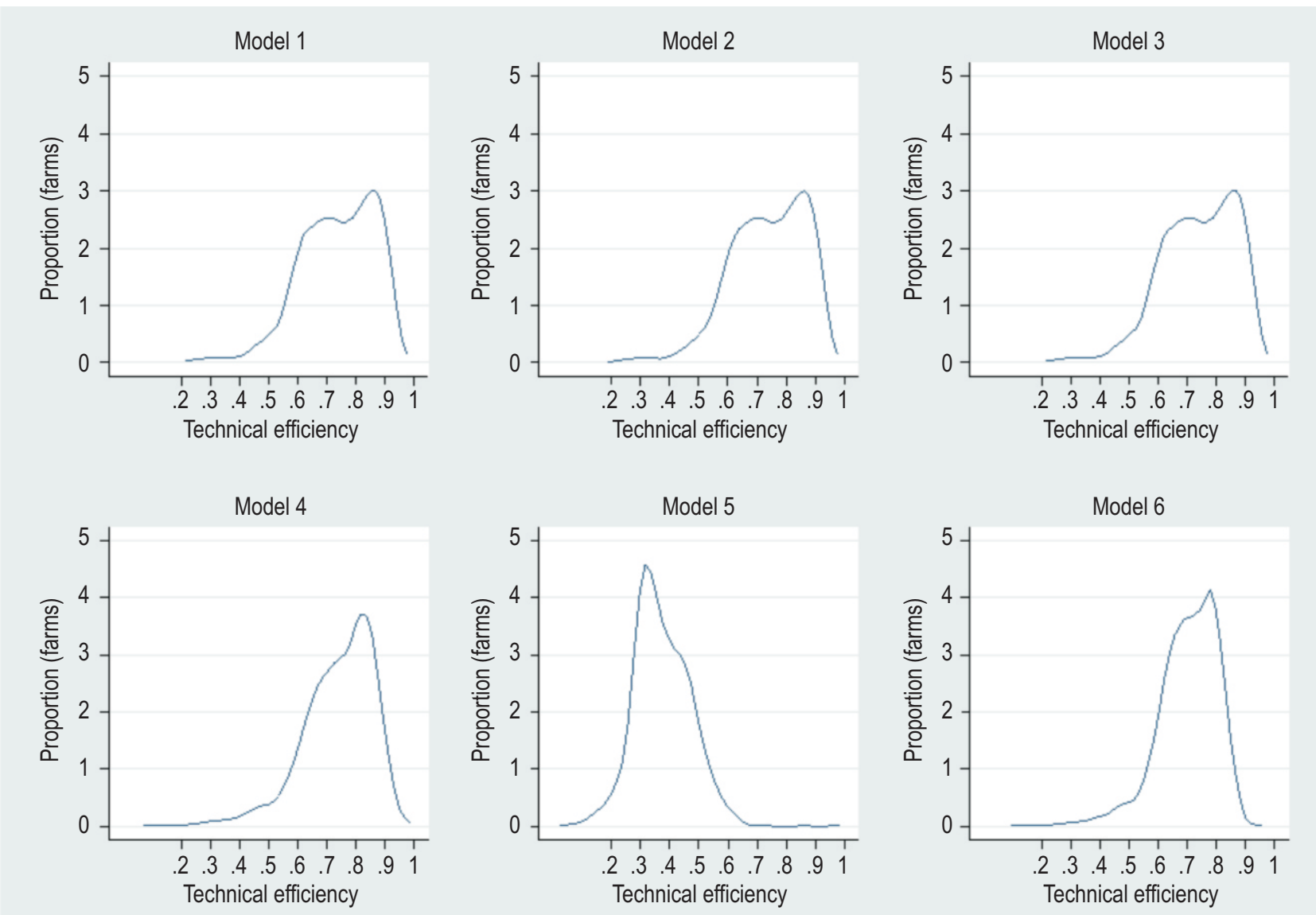

Fig. 1 : Kernal density technical efficiency distribution sugarcane farms for Model 1-6.

Table 2: Log likelihood ratio test

\begin{tabular}{|c|c|c|c|c|c|}
\hline Test & Model 1 & Model 2 & Model 3 & Model 4 & Model 5 \\
\hline LLR & 37.39 & 2074.77 & 2065.55 & 2074.44 & 259.47 \\
\hline \multicolumn{6}{|c|}{ Critical values of mixed Chi-square distribution Significance level } \\
\hline dof & 0.25 & 0.1 & 0.05 & 0.025 & 0.01 \\
\hline 1 & 0.46 & 1.64 & 2.71 & 3.84 & 5.41 \\
\hline
\end{tabular}

Source: Kodde and Palm (1986, Econometrica)

0.957, respectively, indicating that the efficiency scores are rather consistent for these models.

However, the plot between Models 6 and 5 indicates a systematically lower correlation (0.834) and efficiency score in high score group, resulting in non-linear pattern (Fig.3). Finally, the results of log likelihood ratio test indicated that Model 6 had the best fit for data considered for this study (Table.2). This result is consistent with Kumbhakar (2014).

Stochastic frontier : Estimates of different frontier production functions (Model-1 to 6) are presented in Table 3. Based on the log likelihood results, best-suited model results are discussed in this section. The estimated lambda $(\lambda)$ parameter for selected model was 1.15 (Model 6), which means that the total error variance was mainly due to inefficiency, whereas random errors are less important. The $y$ value (57.01 percent) indicates relative variability of one-sided error term to total error-term. Hence, 57.01 $\%$ variation in sugarcane production was due to differences in technical efficiencies remaining due to random errors. These random errors include biotic/abiotic stress during its active growth phases, climatic factors and other factors which are not included in the present model (Singh et al., 2019; Misra et al., 2019; Malaiarasan et al., 2020). It can be observed from Table 3 that 

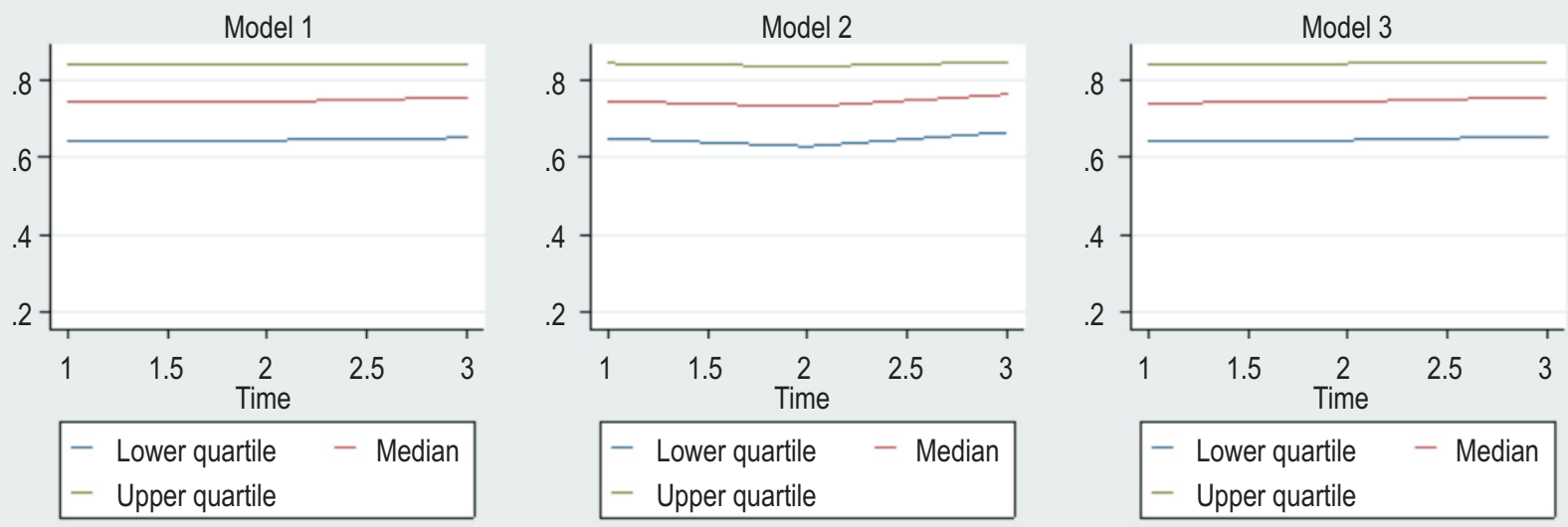

Model 4

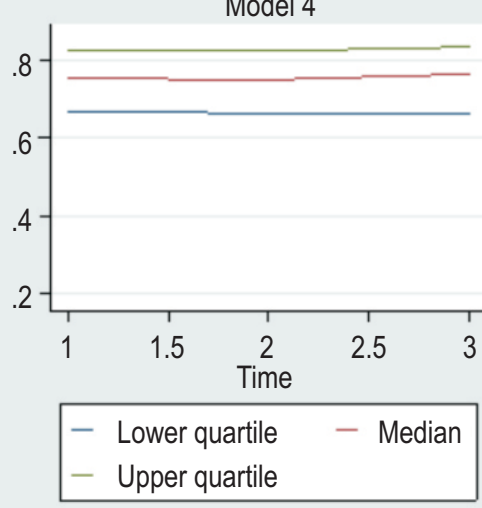

Model 5

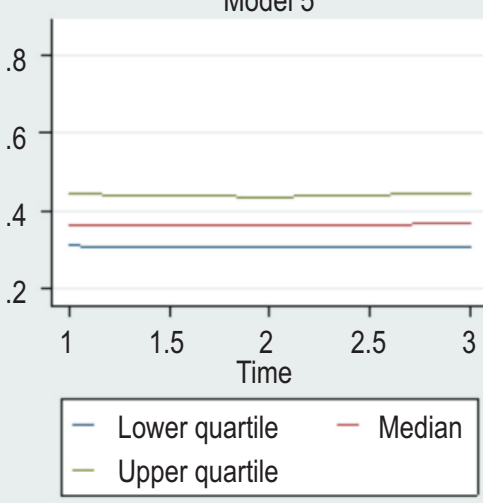

Model 6

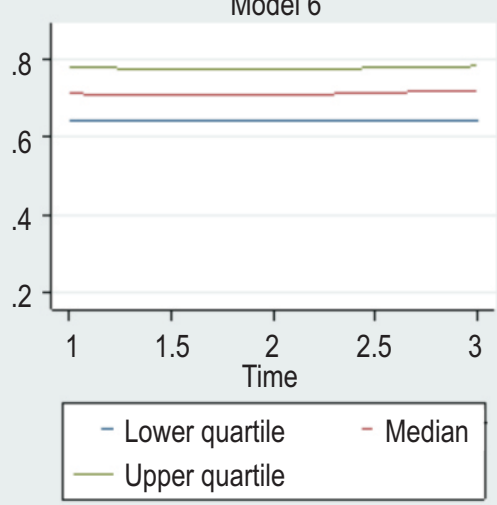

Fig. 2 : Technical efficiency of sugarcane farms over the years for Model 1-6.

variables like area in hectare, machine usage in hours, seed quantity in kilograms, manure usage in quintals and total fertilizer usage in kilograms are significant and positively influence sugarcane production. As expected, it shows a positive relationship between total farm size and production but the coefficients of dummy for farm size reveals that medium and large sugarcane farms have a negative impact on sugarcane production. These results are reflected in Fig. 4 that except small sugarcane farms, medium and large farms have a negative impact on farm size. This shows that medium and large sugarcane farms are less efficient compared to small farms (Hoque, 1988). Though overall machine hours have a positive impact on sugarcane production, the share of own machinehours has a negative impact. It indicates that as compared to own machine-hours, hired machine hours are efficient for sugarcane production because $86.20 \%$ of the farmers in India are small and marginal farmers. As per the Agricultural Census 2015-16, the average size of operational holdings in India is only 1.08 ha. So, owing such a costly machine for cultivating marginal and small farm would not be an efficient one.
The results are similar to Fig. 5 that across all farm sizes, the share of own machine-hours has a negative impact on overall technical efficiency in sugarcane production. The results are in line with the results of Larsén (2010), that hired pieces of machinery are more efficient in production. The return to the elasticity of 0.8655 implies a slight decreasing return to scale, which indicates that the farmers are engaged in sugarcane production on a nonoptimal scale.

Persistent technical efficiency : In 2011-12, the persistent technical efficiency score of Indian sugarcane farmers was 0.84 , it increased to 0.84 in 2012-13 and 0.85 in 2013-14 with a compound annual growth rate of $0.29 \%$. Triennium average persistent technical efficiency score of Indian sugarcane farmers was 0.85 with a growth rate of $0.29 \%$. Among seven states, Haryana and Uttar Pradesh had a negative compound annual growth rate in their persistent technical efficiency. Haryana had the highest negative growth rate in the persistent technical efficiency of sugarcane farmers with a value of $0.83 \%$. It showed that the Haryana and Uttar Pradesh's sugarcane farmers' production efficiency has declined over the years due to better 


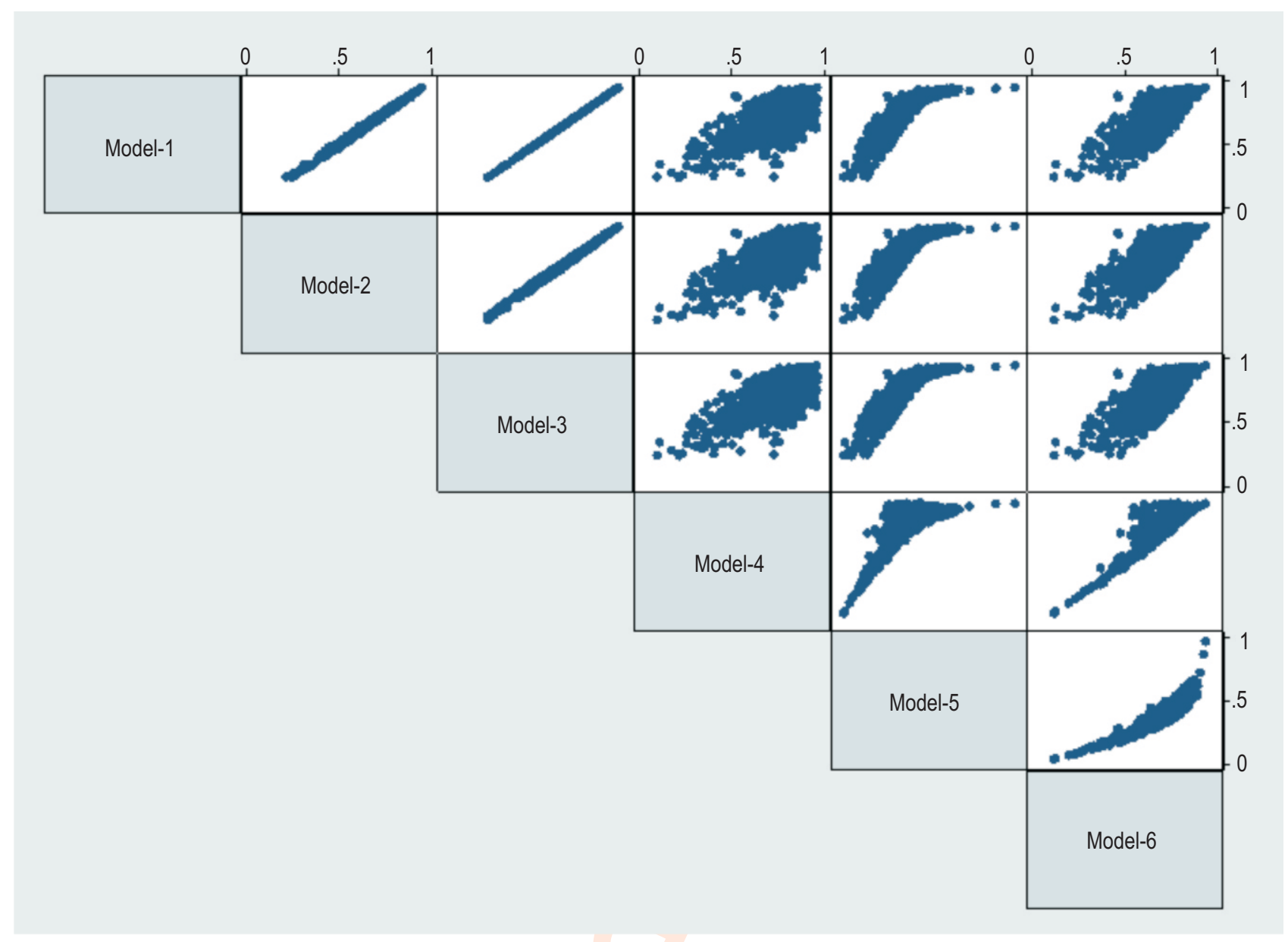

Fig. 3 : Scatter plot matrix of pair wise technical efficiency.

Table 3: Estimates of parameters from different frontier production functions

\begin{tabular}{|c|c|c|c|c|c|c|}
\hline Particulars & Model1 & Model 2 & Model 3 & Model 4 & Model 5 & Model 6 \\
\hline In_ARE & $0.824^{* * *}(0.018)$ & $0.825^{\star * \star}(0.018)$ & $0.824^{* * *}(0.018)$ & $0.827^{* \star \star}(0.017)$ & $0.818^{* * *}(0.019)$ & $0.818^{* * *}(0.019)$ \\
\hline In_ANL & $-0.001^{\mathrm{NS}}(0.005)$ & $-0.001^{\mathrm{NS}}(0.005)$ & $-0.001^{\mathrm{Ns}}(0.005)$ & $-0.003^{\mathrm{Ns}}(0.004)$ & $0.001^{\mathrm{Ns}}(0.005)$ & $0.001^{\mathrm{Ns}}(0.005)$ \\
\hline In_MCN & $0.031^{* * *}(0.007)$ & $0.032^{* * \star}(0.007)$ & $0.031^{* * *}(0.007)$ & $0.038^{* * *}(0.006)$ & $0.031^{* \star \star}(0.007)$ & $0.031^{* * \star}(0.007)$ \\
\hline In_SED & $0.001^{\mathrm{Ns}}(0.005)$ & $0.001^{\mathrm{Ns}}(0.005)$ & $0.001^{\mathrm{Ns}}(0.005)$ & $-0.011^{* *}(0.005)$ & $0.002^{* *}(0.005)$ & $0.002^{\star \star}(0.005)$ \\
\hline In_MRE & $0.024^{* * *}(0.004)$ & $0.025^{* * *}(0.004)$ & $0.024^{* * *}(0.004)$ & $0.033^{* * *}(0.004)$ & $0.022^{* * *}(0.005)$ & $0.022^{* * *}(0.005)$ \\
\hline In_INC & $0.002^{\mathrm{NS}}(0.003)$ & $0.003^{\mathrm{NS}}(0.003)$ & $0.002^{\mathrm{NS}}(0.003)$ & $0.003^{\mathrm{NS}}(0.002)$ & $0.002^{\mathrm{NS}}(0.003)$ & $0.002^{\mathrm{NS}}(0.003)$ \\
\hline In_FER & $0.248^{* * *}(0.013)$ & $0.248^{* * *}(0.013)$ & $0.249^{* * *}(0.013)$ & $0.260^{* * *}(0.012)$ & $0.257^{* * *}(0.013)$ & $0.257^{* * *}(0.013)$ \\
\hline In_SMC & $-0.050^{\star \star \star}(0.016)$ & $-0.050^{* * *}(0.016)$ & $-0.050^{\star * *}(0.016)$ & $0.028^{\mathrm{NS}}(0.019)$ & $-0.054^{\mathrm{NS}}(0.016)$ & $-0.054^{* * *}(0.016)$ \\
\hline SDU2 & $-0.080^{* * \star}(0.028)$ & $\left.-0.08^{* * *} 027\right)$ & $-0.079^{* * \star}(0.028)$ & $-0.110^{* * *}(0.025)$ & $-0.078^{* * *}(0.028)$ & $-0.078^{* * *}(0.028)$ \\
\hline SDU3 & $-0.216^{* * *}(0.047)$ & $-0.215^{\star * *}(0.047)$ & $-0.215^{* * *}(0.047)$ & $-0.240^{* * *}(0.042)$ & $-0.208^{* * *}(0.048)$ & $-0.208^{* * *}(0.048)$ \\
\hline Constant & $5.378^{\star * \star}(0.073)$ & $5.378^{* * *}(0.073)$ & $5.374^{\star * \star}(0.073)$ & $5.339^{\star * \star}(0.07)$ & $4.991^{* * *}(0.071)$ & $4.991^{* * *}(0.071)$ \\
\hline $\operatorname{Sigma}^{2} u()$ & $2.556^{\star \star \star}(0.044)$ & $2.862^{\star \star *}(0.044)$ & $2.556^{\star \star \star}(0.044)$ & $2.743^{\star \star *}(0.078)$ & $2.743^{\star \star \star}(0.078)$ & $3.993^{* * \star}(0.085)$ \\
\hline \multirow[t]{3}{*}{$\operatorname{Sigma}^{2} v()$} & $1.738^{* * *}(0.093)$ & $2.596^{* * *}(0.498)$ & $1.764^{* \star \star}(0.106)$ & $1.608^{* * *}(0.088)$ & $2.707^{\star \star \star}(0.083)$ & $3.011^{* \star *}(0.132)$ \\
\hline & 1.213 & 1.050 & 1.204 & 1.306 & 1.007 & 1.152 \\
\hline & 59.525 & 52.437 & 59.167 & 63.043 & 50.330 & 57.010 \\
\hline
\end{tabular}

Note: *** indicates one percent significant level; ** indicates five percent significant level and NS indicates Non significant 


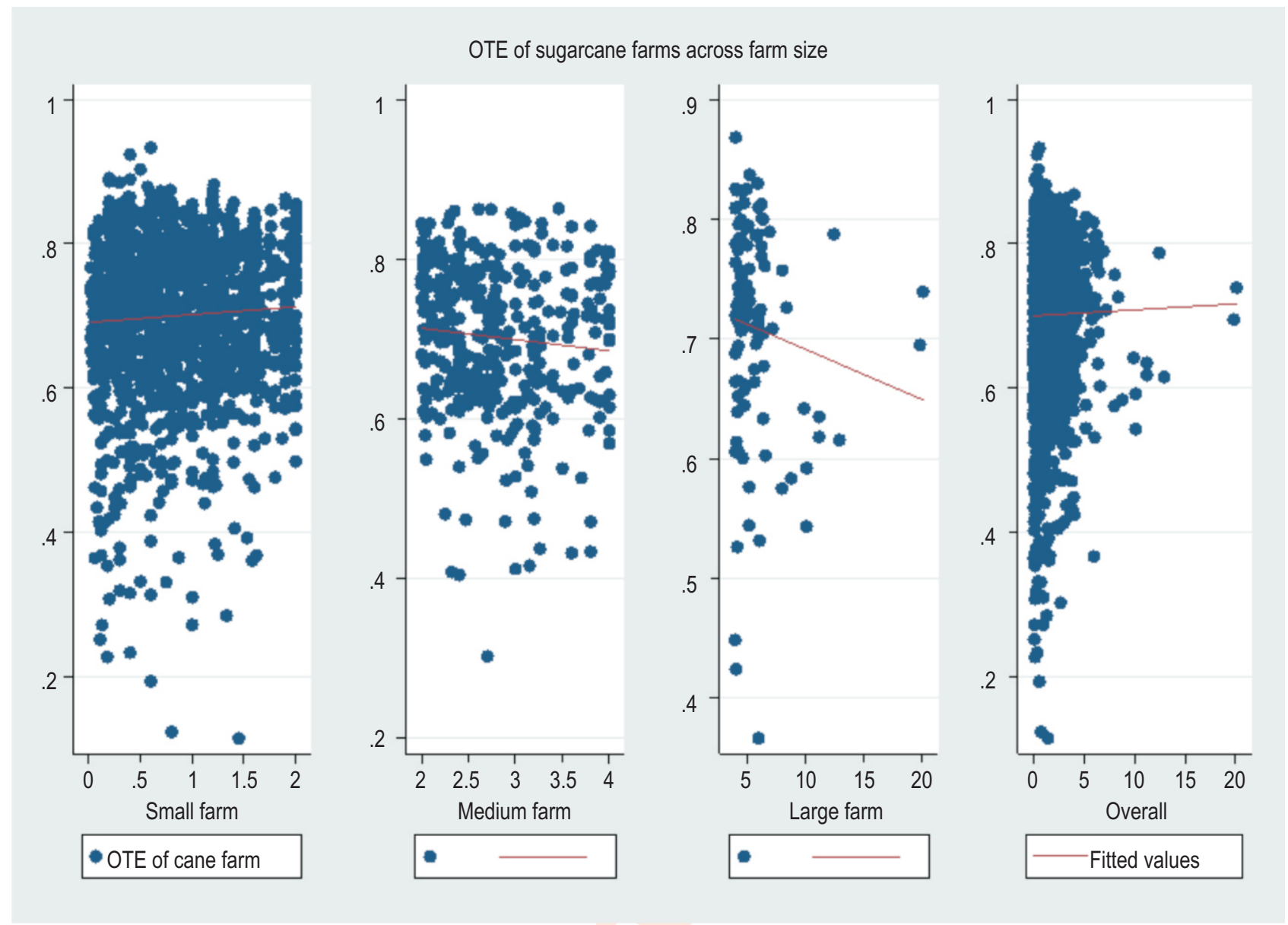

Fig. 4 : Overall technical efficiency of sugarcane farms across farm size.

returns from the paddy-wheat combination as compared to sugarcane, and also due to long maturing period of sugarcane, farmers are shifting to intercropping with onion, wheat, gram, garlic, etc. to earn extra income. Among seven states, Uttaranchal sugarcane farmers have the highest growth rate in the persistent technical efficiency with $1.81 \%$, followed by Karnataka (1.60\%), Andhra Pradesh (1.55\%), Maharashtra $(0.79 \%)$ and Tamil Nadu (0.05\%). Though, Tamil Nadu sugarcane farmers rank fifth in the growth rate of persistent technical efficiency, it ranks first in the triennium persistent technical efficiency score with 0.89 . In contrast, though Uttaranchal has the highest growth rate of persistent technical efficiency in sugarcane production, it ranks last in the triennium persistent technical efficiency score (0.80) among seven states. It reveals that Uttaranchal has a vast scope in increasing its persistent technical efficiency.

Triennium average residual technical efficiency of Indian sugarcane farmers is 0.83 with a positive growth rate of $0.18 \%$. Except for Haryana and Tamil Nadu, all the states included in the model have a positive growth rate of residual technical efficiency in sugarcane production. Haryana has the highest negative growth rate of $1.67 \%$, followed by Tamil Nadu with $0.70 \%$. Labor shortage may be a reason for the shortfall of their residual technical efficiency. Among the seven states, Karnataka has the highest positive growth rate with $4.95 \%$ followed by Uttaranchal (2.21\%), Maharashtra (0.58\%), Uttar Pradesh $(0.43 \%)$ and Andhra Pradesh (0.03\%). Among the states, Tamil Nadu ranks first in residual technical efficiency score with 0.85. Though, Tamil Nadu ranks first, it has a negative growth rate in residual technical efficiency. Andhra Pradesh ranks second with a score of 0.85 followed by Karnataka (0.83), Maharashtra (0.82), Haryana (0.82), Uttar Pradesh (0.81) and Uttaranchal (0.80).

Indian farmer's overall technical efficiency in sugarcane production is 0.70 with a positive growth rate of $0.47 \%$. Among the seven states, Tamil Nadu has the highest overall technical efficiency score in sugarcane production with 0.76 but with a negative growth rate of $0.59 \%$. It shows that Tamil Nadu farmer's overall technical efficiency in sugarcane production is declining. Andhra Pradesh (0.75) ranks second with a positive growth rate of $1.64 \%$, followed by Karnataka $(0.70)$ with a positive growth rate 
OTE of sugarcane farms and share of own machine hours across farm size
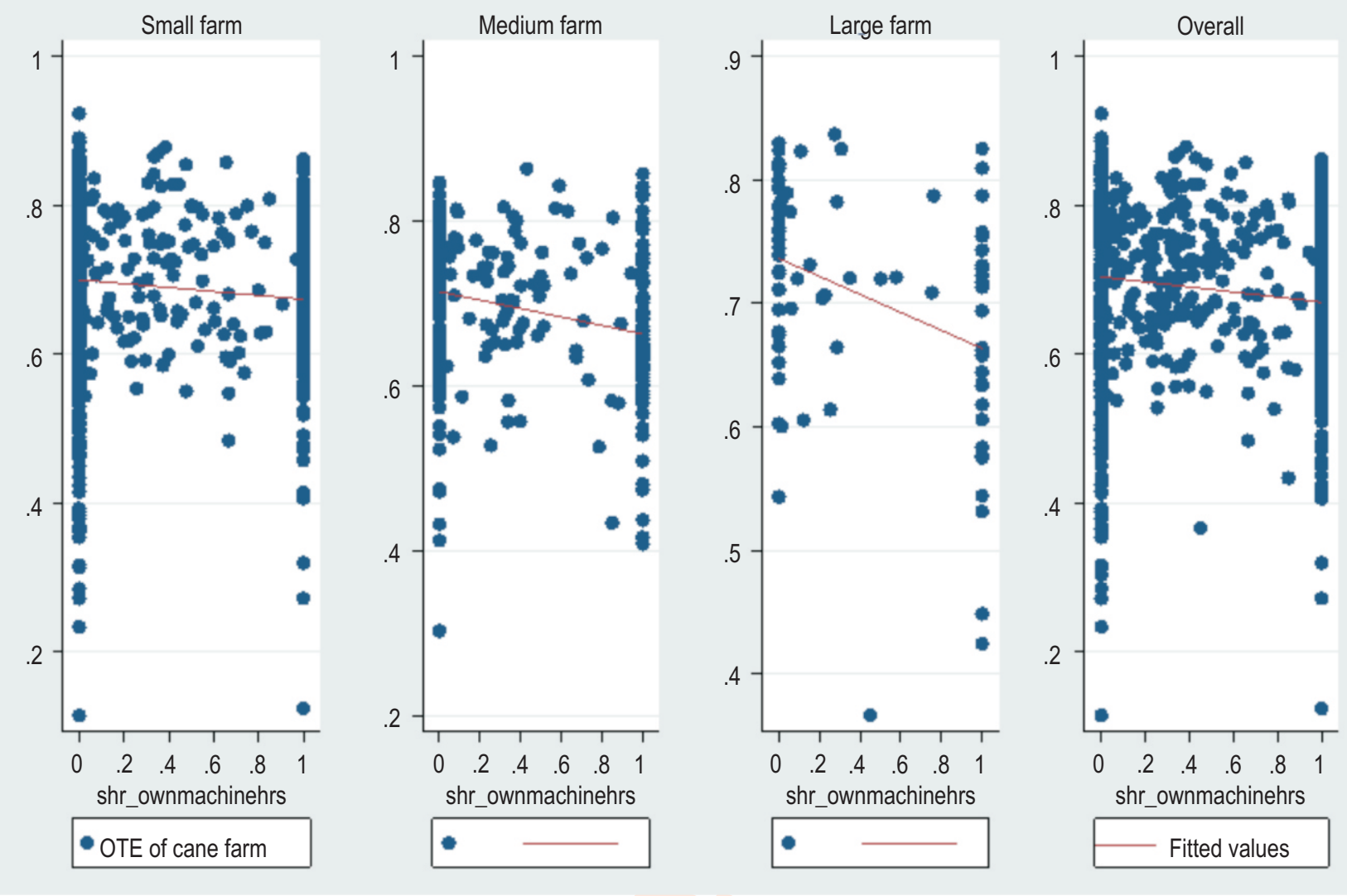

Fig. 5: Overall technical efficiency of sugarcane farms and share of own machine hours across farm size.

of $6.09 \%$, Maharashtra $(0.70)$ with a positive growth rate of $1.43 \%$, Haryana ( 0.67 ) with a negative growth rate of $2.44 \%$, Uttar Pradesh (0.66) with a positive growth rate of $0.20 \%$ and Uttaranchal (0.64) with a positive growth rate of $3.93 \%$, respectively.

The variable total fertilizer usage has a positive and high elasticity of sugarcane production. Being a long-duration crop, its nutritional requirements are high. Appropriate measures need to be taken to increase the use of fertilizers. Though machinery usage increases the yield of sugarcane, the share of own machine usage has a negative impact on yield. Hence, the starting of Agricultural Machinery Custom Hiring Centres (CHC) in each district will benefit the farmers, especially small and marginal farmers. India's overall technical efficiency in sugarcane production is 0.70 . It indicates that sugarcane yield could be increased by $30 \%$, through proper input management. Among the seven states, Uttaranchal has the highest scope of improving the sugarcane yield with 36\%, followed by Uttar Pradesh (34\%), Haryana (33\%), Maharashtra (30\%), Karnataka (30\%), Andhra Pradesh (25\%) and Tamil Nadu (24\%). Hence, the necessary action should be taken to increase their technical efficiency in sugarcane production.

\section{Acknowledgment}

I deeply acknowledge the Principal Investigator, Dr. M. Umanath, MIDS Chennai to pen this article.

\section{References}

Ambetsa, F.L., S.C. Mwangi and S.N. Ndirangu: Technical efficiency and its determinants in sugarcane production among smallholder sugarcane farmers in Malava sub-county, Kenya. African J. Agric. Res., 15, 351-360 (2020).

Banik, A.: Technical Efficiency of irrigated farms in a village of Bangladesh. Indian J. Agric. Eco., 49, 70-79 (1994).

Battese, G.E. and T.J. Coelli: Frontier production functions, technical efficiency and panel data: With application to paddy farmers in India. J. Productivity Anal., 3, 153-169 (1992).

Colombi, R., S.C. Kumbhakar, G. Martini and G. Vittadini: Closed-skew normality in stochastic frontiers with individual effects and long/short-run efficiency. J. Productivity Anal., 42, 123-136 (2014).

Dlamini, S., J.I. Rugambisa, M.B. Masuku and A. Belete: Technical 
efficiency of the small-scale sugarcane farmers in Swaziland: A case study of Vuvulane and Big bend farmers. African J. Agric. Res., 5, 935-940 (2010).

FAOSTAT, FAO.: Statistical data. Food and Agriculture Organization of the United Nations, Rome (2017).

Felix, K.T., S.M. Gopal, K.R. Ashok, S. Panneerselvam and M.R. Duraisamy: Technical efficiency of maize production in different vulnerable agro climatic zones of Tamil Nadu. J. Pharma. Phytochem., 7, 498-502 (2018).

Greene, W.: Reconsidering heterogeneity in panel data estimators of the stochastic frontier model. J. Eco., 126, 269-303 (2005).

Hoque, A.: Farm size and economic-allocative efficiency in Bangladesh agriculture. App. Eco., 20, 1353-1368 (1988).

Jondrow, J., C.K. Lovell, I.S. Materov and P. Schmidt: On the estimation of technical inefficiency in the stochastic frontier production function model. J. Eco., 19, 233-238 (1982).

Kalirajan, K.P. and S.T. Shand: A generalized measure of technical efficiency. App. Eco., 21, 25-34 (1989).

Kumbhakar, S.C. and A. Heshmati: Efficiency measurement in Swedish dairy farms: An application of rotating panel data, 1976-88. American J. Agric. Eco., 77, 660-674 (1995).

Kumbhakar, S.C. and L. Hjalmarsson: Labour use efficiency in Swedish social insurance offices. J. App. Eco., 10, 33-47 (1995).

Kumbhakar, S.C. and L. Hjalmarsson: Technical efficiency and technical progress in Swedish Dairy Farms. The measurement of productive efficiency-techniques and applications. New York, Oxford, pp. 256-270 (1993).

Kumbhakar, S.C., G. Lien and J.B. Hardaker: Technical efficiency in competing panel data models: a study of Norwegian grain farming. J. Product. Anal., 41, 321-337 (2014).

Kumbhakar, S.C.: Production frontiers, panel data, and time-varying technical inefficiency. J. Eco., 46, 201-211 (1990).

Larsén, K.: Effects of machinery sharing arrangements on farm efficiency: evidence from Sweden. Agric. Eco., 41, 497-506 (2010).

Malaiarasan, U., K.T. Felix, R. Paramasivam and S.J. Balaji: Sugar price determination in India: An econometric analysis. Agric. Eco. Res. Rev., 32, 165-174(2019).

Malaiarasan, U., R. Paramasivam, K. T. Felix and S. J. Balaji: Simultaneous equation model for Indian sugar sector. J. Soci.
Econ. Develop., 22, 1-29 (2020).

Misra, A.K. Mall, A.K. Shrivastava, S. Solomon, S.P. Shukla and Mohd. I. Ansari: Assessment of Leuconostoc spp. invasion in standing sugarcane with cracks internode. J. Environ. Biol., 40, 316-321 (2019).

MOSPI.: Statistical Yearbook India (2018). Retrieved from http://mospi.nic.in/statistical-year-book-india/2018

Mundlak, Y.: Empirical production function free of management bias. $J$. Farm Eco., 43, 44-56 (1961).

Parikh, A. and K. Shah: Measurement of technical efficiency in the North West Frontier Province of Pakistan. J. Agric. Eco., 45, 132-138 (1994).

Pitt, M.M. and L.F. Lee: The measurement and sources of technical inefficiency in the Indonesian weaving industry. J. Develop. Eco., 9, 43-64 (1981).

Rao, I.V.Y.: Efficiency, yield gap and constraints analysis in irrigated visà-vis rainfed sugarcane in North Coastal Zone of Andhra Pradesh. Agric. Eco. Res. Rev., 25, 167-171 (2012).

Rios, A.R. and G.E. Shively: Farm size and nonparametric efficiency measurements for coffee farms in Vietnam (2005).

Schmidt, P. and R.C. Sickles: Production frontiers and panel data. J. Busi. Eco. Stat., 2, 367-374 (1984).

Sekhon, M.K., A.K. Mahal, M. Kaur and M.S. Sidhu: Technical efficiency in crop production: A region-wise analysis. Agric. Eco. Res. Rev., 23, 366-374 (2010).

Shanthy, T.R.: Strategies for effective dissemination of appropriate technologies to sugarcane growers in India. Sugar Tech, 13, 354359 (2011).

Singh, S., S.P. Singh, A.D. Pathak and N. Pandey: Assessment of waterlogging induced physio-biochemical changes in sugarcane varieties and its association with water logging tolerance. $J$. Environ. Biol., 40, 384-392 (2019).

Solomon, S.: The Indian sugar industry: An overview. Sugar Tech, 13, 255-265 (2011).

Surendran, U., V. Ramesh, M. Jayakumar, S. Marimuthu and G. Sridevi: Improved sugarcane productivity with tillage and trash management practices in semi-arid tropical agro ecosystem in India. Soil Tillage Res., 158, 10-21 (2016).

Thomas, K. and R. Sundaresan: Economic efficiency of rice production in Kerala. Bihar J. Agric. Market., 8, 310-315 (2000). 